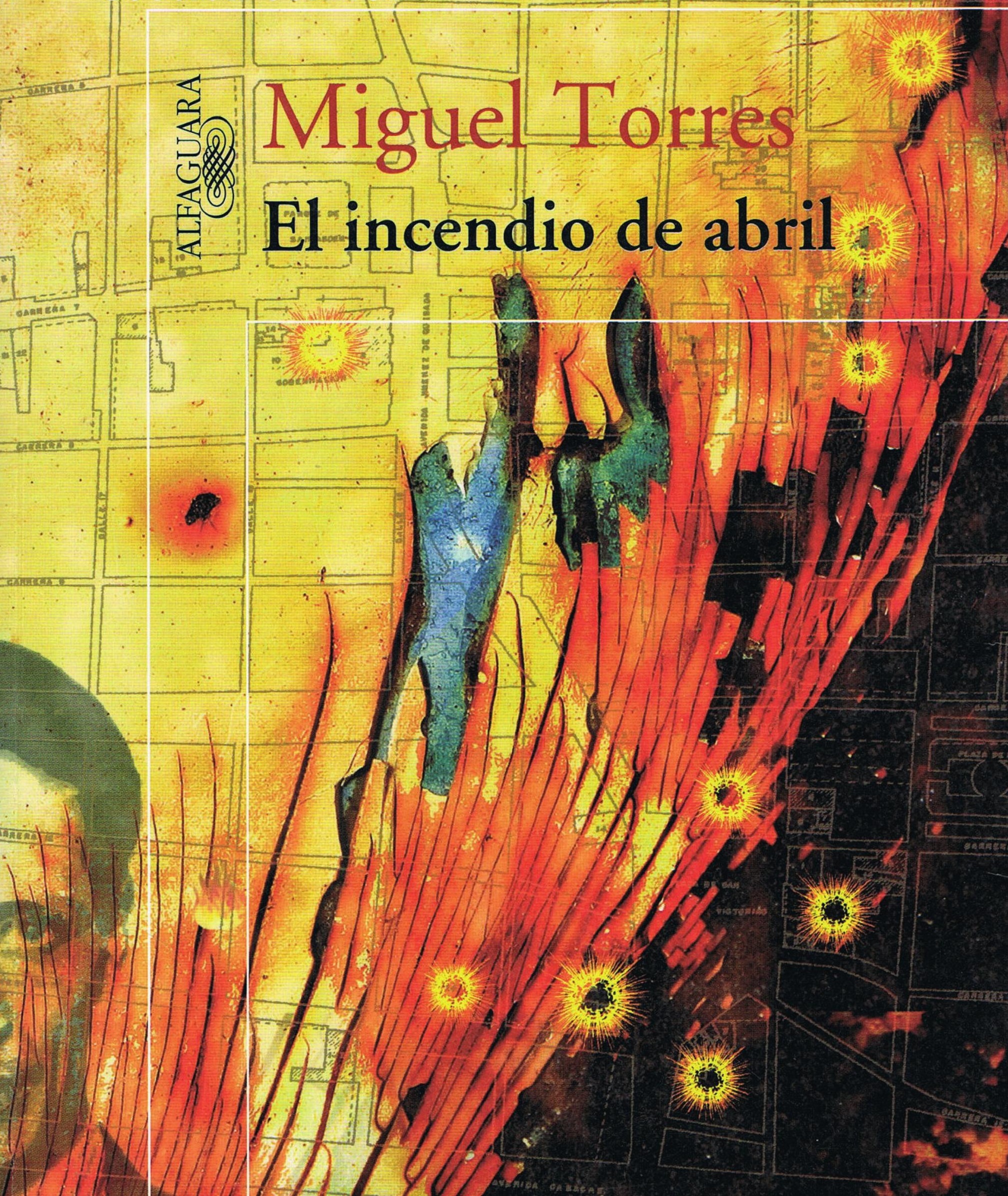




\section{Una lectura sociocrítica de El incendio de abril, de Miguel Torres y La sombra de Orión, de Pablo Montoya Campuzano}

\section{Artículo de investigación}

Recibido: 22 de marzo de 2021

Aprobado: 14 de agosto de 2021

\section{Jhon Erick Cabra Hernández}

Secretaría de Educación, Bogotá, Colombia. jecabrahz@gmail.com

Cómo citar este artículo: Cabra Hernández, Jhon Erick (2022). Una lectura sociocrítica de El incendio de abril, de Miguel Torres y La sombra de Orión, de Pablo Montoya Campuzano. Estudios Artísticos: revista de investigación creadora, 8(12) pp. 130145. DOI: https://doi.org/10.14483/25009311.18768

$$
<
$$

Portada del libro: El incendio de abril. Miguel Torres. Editorial Alfaguara

\section{(c) (i)}

https://creativecommons.org/licenses/by/4.0/deed.es

\section{Resumen}

La siguiente reflexión se propone realizar una lectura desde la sociocrítica, con el fin de observar cómo la realidad referencial se transforma de manera semiótica a partir de ciertas estructuras formales en la escritura del texto de ficción. Para lograr este objetivo se toma la noción ideosema como el articulador que determina la presencia de lo no-discursivo (prácticas sociales) y la relación de los discursos establecidos, reproducidos y replicados en lo discursivo (el texto de ficción). En ese sentido, propongo que el testimonio, como práctica y representación, es un ideosema estructurante en la configuración narrativa de EI incendio de abril, de Miguel Torres y La sombra de Orión, de Pablo Montoya Campuzano. De esta manera, el documento se organiza de la siguiente manera: 1. Definición de los aspectos conceptuales que fueron tomados de la sociocrítica crosiana. 2. Explicación de algunos de los aspectos que definen a la novela-testimonio y la novela intrahistórica y que, para los fines de este texto, sirven como ideosemas estructurantes en la construcción narrativa de las dos novelas seleccionadas. 3 . Aplicación de los aspectos conceptuales al corpus seleccionado.

\section{Palabras clave}

Sociocrítica; ideosema; sujeto cultural; intrahistoria; literatura testimonial 


\section{A socio-critical reading of El incen- dio de abril, by Miguel Torres, and La sombra de Orión, by Pablo Montoya Campuzano}

\begin{abstract}
The following reflection carries out a reading from socio-criticism to point out how referential reality is transformed in a semiotic way from certain formal structures in the writing of the fictional work. To achieve this objective, the concept of ideoseme is taken as the articulator that determines the presence of non-discursive elements (social practices) and the relationship of the discourses that have been established, reproduced and replicated in the discursive realm (the fictional text). In this sense, I propose that testimony, as practice and representation, is a structuring ideoseme in the narrative configuration of El incendio de abril, by Miguel Torres and La sombra de Orión, by Pablo Montoya Campuzano. In this way, the article is organized as follows: 1. Definition of the conceptual aspects that were taken from Crosian socio-criticism. 2. Explanation of some of the aspects that define the testimony-novel and the intrahistoric novel and that for the purposes of this article, serve as structuring ideosemes in the narrative construction of the two selected novels. 3. Application of the conceptual aspects to the selected corpus.
\end{abstract}

\section{Keywords}

Socio-criticism; ideoseme; cultural subject; intrahistory; testimonial literature

\section{Une lecture socio-critique de EI incendio de abril, de Miguel Torres, et La sombra de Orión, de Pablo Montoya Campuzano}

\section{Résumé}

La réflexion qui suit effectue une lecture à partir de la sociocritique pour montrer comment la réalité référentielle se transforme de manière sémiotique à partir de certaines structures formelles dans l'écriture de l'œuvre fictionnelle. Pour atteindre cet objectif, le concept d'idéosème est pris comme l'articulateur qui détermine la présence d'éléments non discursifs (pratiques sociales) et la relation des discours qui ont été établis, reproduits et répliqués dans le domaine discursif (le texte de fiction). En ce sens, je propose que le témoignage, comme pratique et représentation, est un idéosème structurant dans la configuration narrative de $E I$ incendio de abril, de Miguel Torres et La sombra de Orión, de Pablo Montoya Campuzano. Ainsi, l'article est organisé comme suit : 1. Définition des aspects conceptuels qui ont été repris de la sociocritique crosienne. 2. Explication de certains des aspects qui définissent le roman-témoignage et le roman intrahistorique et qui, aux fins de ce texte, servent d'idéosèmes structurants dans la construction narrative des deux romans sélectionnés. 3. Application des aspects conceptuels au corpus sélectionné.

\section{Mots clés}

Sociocritique ; idéosème ; sujet culturel ; intrahistoire ; littérature de témoignage

\section{Uma leitura sociocrítica de El incen- dio de abril, de Miguel Torres y La sombra de Orión, de Pablo Montoya Campuzano}

A seguinte reflexão se propõe a realizar uma leitura a partir da sociocrítica, com o fim de observar como a realidade referencial se transforma de maneira semiótica a partir de certas estruturas formais na escrita de um texto de ficção. Para alcançar este objetivo se toma a noção de ideosema como o articulador que determina a presença do não-discursivo (práticas sociais) e a relação dos discursos estabelecidos, reproduzidos e replicados no discursivo (o texto de ficção). Neste sentido, proponho que o testemunho, como prática e representação, é um ideosema estruturante na configuração narrativa de El incendio de abril, de Miguel Torres y La sombra de Orión, de Pablo Montoya Campuzano. Desta maneira, o documento se organiza do seguinte modo: 1-Definição dos aspectos conceituais que foram retirados da sociocrítica crosiana. 2.Explicação de alguns dos aspectos que definem a novela-testemunho e a novela intra-histórica e que, para os fins deste texto, servem como ideosemas estruturantes na construção narrativa das duas novelas selecionadas. 3. Aplicação dos aspectos conceituais ao corpus selecionado. 


\section{Palavras chave}

Sociocrítica; ideosema; sujeito cultural; intra-história; literatura de testemunho

\section{Sug simi rimai, kasa suti kunuriska kai killa abril ruraska Miguel Torres suti chasallata kilkaska Pablo Montoya Campuzano suti}

\section{Maillallachiska}

luiasunchi ka kilkaita kawaspa kaipi munaku ruranga pai kausaskapi pasariskata chasallata ñugpata kausaskata mana chingangapa chasa muna chukanga apachiskasina. Chi allilla llugsingapa churangapa chrankuna Achka kilkaikuna llukami llapa codigokuna mana llapa ullarikuna tiangapa paikuna churaska chasa allilla llugsingami iuiarispa kawachiku parlaku imasami pai kikin ruraspa churra pangapi kilkaska kai suti kunuriska kai killa suti abril, ruraska runa suti Miguel Torres, Pablo Montoya Campuzanu ruraska. Chi nispa kasa churaska sug ima kaska kai kikin kawaskapi tiaska suti. Iskai iachachiku mailla sugnimanda ruraska nispa kawachingapa, parlangapa ñugpamandata pangapi churaskata kai iskai kilkaita sakingapa kimsa: kakui allilla sumaglla kidangapa kai sakiskata.

\section{Rimangapa Ministidukuna}

Sociocritica Nukanchipa Llagtapi pasariskata; ideosema Achka ruraikuna; nukakinkinmanda parlu; Nukanchipa kausaimanda; ima pasariskata parlai

\section{I}

\section{Aspectos conceptuales}

La sociocrítica ${ }^{1}$ de Edmond $\mathrm{Cros}^{2}$ se preocupa por la relación que se establece entre el texto cultural

\footnotetext{
1 Al respecto: "El quehacer de la sociocrítica como práctica transdisciplinar, en tanto que su metodología podría ser calificada como "fronteriza", es decir, por la característica que posee esta teoría, capaz de abordar diferentes géneros a la par de establecer un diálogo con otras disciplinas". (Cros, 2003).

2 En el mismo periodo en el que se desarrollan Los Cultural Studies en Birminghan (1964), se desarrolla en Montpellier las bases de la sociocrítica de Edmond Cros en el Instituto de Investigación Intersitio y Estudios Culturales (Universidad Paúl Valery). Asimismo, La sociocrítica permite: "El fecundo diálogo disciplinar teórico-crítico de esta vía de conocimiento, la construcción de dispositivos de conocimiento de
}

y el campo social e histórico en donde este se produce. De tal manera, termina siendo una herramienta metodológica que permite analizar cómo lo social se transcribe, en este caso, en el texto literario y así permite estudiar:

La problemática de la creación artística y de la representación de la historia desde el punto de vista de su incorporación en el espacio imaginario multidimensional del sujeto cultural. En el marco de la herencia estructuralista, se interesa por las formas porque para él (para Cros) a este nivel es donde se opera la inscripción de lo social. (Pascal Kadio, 2017, p. 194)

En este sentido, resulta interesante analizar el punto de encuentro que se establece entre la infraestructura económica y la superestructura ideológica a la cual pertenece la literatura como producto cultural.

Siguiendo este orden de ideas, se puede decir al respecto de la sociocrítica planteada por Edmond Cros que:

Bajo el efecto de la escritura, la realidad referencial sufre un proceso de transformación semiótica que codifica este referente bajo forma de elementos estructurales y formales. Este proceso se asigna como tarea la reconstrucción del conjunto de mediaciones que deconstruyen, desplazan, reorganizan y resemantizan las diferentes representaciones de lo vivido individual y colectivo. (Pascal Kadio, 2017, p. 195)

Tales mediaciones provienen del discurso social y de lo transhistórico, además del acto de la enunciación desde el campo literario y artístico. De esta manera, la morfogénesis de los objetos culturales se constituye a partir de trazados ideológicos dispersos a lo largo del texto. La sociocrítica, como interdisciplina, permite el análisis de microsemióticas intratextuales que develan interrelaciones entre los textos literarios o culturales y las estructuras sociales e ideológicas que los sustentan. Vale la pena aclarar que dichas interrelaciones se pueden

proyección semiótica, válidos para el estudio de cualesquiera clases de signos, y la radical apertura por lo que respecta al dominio de estudio que han hecho de la sociocrítica una de las corrientes de mayor aplicación sobre el dominio de la particularidad de cuantas concurren hoy en el ámbito de los estudios literarios y culturales". (Chicharro, 2012, p. 65) 
observar a través de lo que el texto transcribe de la cultura en el nivel de la forma y, evidentemente, del contenido.

Hay que recordar que Edmond Cros retoma algunos de los planteamientos de autores como Michael Foucault, Ronald Barthes, Mijail Bajtin, György Lucáks, Pierre Bourdieu, Émile Benveniste, Jacques Lacan y Lucien Goldman para construir la noción denominada sujeto cultural. ${ }^{3} \mathrm{Al}$ respecto, vale la pena precisar que este concepto hace referencia a:

[...] las modalidades de funcionamiento de un sujeto ideológico, su emergencia, su historia, su naturaleza. Su definición como sistema semiótico-ideológico permite entender y valorar sus impactos en la morfogénesis de los productos culturales y la importancia de su intervención en el origen socioideológico de las formas. [...] se refiere a un espacio complejo, heterogéneo, conflictivo; a una totalidad dentro de la cual los elementos dominantes alternan los unos con los otros, en cuyo seno resultan constantemente redistribuidos los trazados semiótico-ideológicos de una serie de sujetos transindividuales cuya cantidad de importancia varían con arreglo a individuos. (Cros, 2003, pp. 27-28)

De la misma manera, el sujeto cultural puede ser considerado como una entidad abstracta manifestada por medio del lenguaje, que devela una subjetividad particular. Así pues, tal noción puede observarse como un lugar de tensión entre formas de dominación y resistencia. Es posible aseverar que, desde la sociocrítica propuesta por Edmond Cros, el texto (en este caso las dos novelas) hace que lo referenciado de la realidad se transforme semióticamente $y$, al hacerlo, se codifique en particularidades en la forma estructural.

3 El sujeto cultural es: "Una instancia que integra a todos los individuos de una misma colectividad: en efecto, su función objetiva es integrar a todos los individuos en un mismo conjunto al tiempo que los remite a sus respectivas posiciones de clase, en la medida en que, como ya he dicho, cada una de esas clases sociales se apropia de ese bien colectivo de diversas maneras. La cultura es una realidad primera. Se le podría aplicar la fórmula utilizada por Althusser referente a la ideología y afirmar que ella me interpela como sujeto, fórmula que equivale, de hecho, a plantear la cuestión del advenimiento del sujeto y de su alienación por un ya aquí ideológico, inscrito tanto en las prácticas sociales e institucionales como en el lenguaje". (Cros," 2003).
Asimismo, dicho sujeto cultural se estructura a partir de una instancia de discurso ocupada por un "Yo", la emergencia y el funcionamiento de una subjetividad, un sujeto colectivo y un proceso de sumisión ideológica. Así pues, este sujeto cultural se vierte en las conciencias particulares de los individuos por medio de prácticas discursivas concretas (discursos políticos, religiosos, culturales, de género, entre otras). Ahora bien, vale la pena preguntarse acerca del cómo opera dicho sujeto cultural, en este caso específico, en los textos de ficción. Al respecto, el hispanista francés es claro al plantear que dicho sujeto cultural opera en/y por la performancia discursiva ${ }^{4}$ (Cros, 2003). Tal operatividad la aborda el autor desde dos hipótesis que son complementarias. La primera, hace alusión a que el lenguaje y la cultura son dos nociones co-extensivas, por lo menos si por el lenguaje se hace referencia a todos los sistemas significantes de una sociedad determinada contemplada en un momento preciso de su evolución histórica (lenguaje + prácticas semióticas diversas y múltiples). La segunda, nos plantea que por el lenguaje es como el hombre se constituye como sujeto.

En este sentido, mi interés es analizar cómo opera esta categoría en El incendio de abril y La Sombra de Orión. Teniendo en cuenta que este opera en/y por el discurso, sugiero que el uso de formas testimoniales en la construcción narrativa, configuran ideosemas estructurantes que permiten observar un sujeto cultural intrahistórico. Por lo tanto, esta noción me servirá para nombrar un mecanismo de sujeción y subjetivación que designa un "yo" en tanto una instancia discursiva, como para nombrar a un sujeto colectivo en una sociedad concreta. Al sujeto no le queda más salida que identificarse cada vez más con los diferentes lugartenientes que lo presentifican en su discurso y, de esa manera, dicho sujeto está atado a la cultura y, de manera directa, depende de ella a través de una subjetividad y ciertos modelos culturales.

\footnotetext{
4 El discurso hace referencia a: "La especificidad discursiva de un sujeto transindividual, lo cual me lleva a definir como interdiscursividad el conjunto de las prácticas adquiridas -esencialmente en un contexto de interlocución- por un sujeto que, como todos los sujetos, ha atravesado y sigue atravesando varios y diversos sujetos transindividuales; esa interdiscursividad, así definida, constituye su competencia, noción que para mí atañe al habla y no a la lengua". (Cros, 2003, p. 15)
} 
Ahora bien, al tomar prestada la categoría ideosema de la sociocrítica crosiana, se hace necesario definirla. Entonces, es posible afirmar que este concepto funciona como un instrumento metodológico que permite el análisis sociotextual. En él se da el enlace de lo semiótico (practica social, extratextual) y lo discursivo (interdiscursividad, intratextualidad). Dicho esto, en el ideosema confluyen ambas formas de estructuraciones. Ahora bien, a la red de ideosemas es a lo que Cros llama microsemiótica intratextual. El ideosema es el lugar de origen de la estructuración textual. Por ende, la red que se constituye (microsemiótica textual) es concebida por el hispanista francés como una estructuración dinámica.

En este sentido, el ideosema, es una noción de análisis textual. Según el autor, el texto de ficción es una multiplicidad de representaciones, un conjunto de varios sistemas que se articulan a partir de una estructura, lo que le otorga una forma particular y genera la literariedad. Dicha estructura en sus múltiples superposiciones de articulaciones, en definitiva, genera un sistema semiótico. Este contiene en sí mismo múltiples microsemióticas discursivas que son pequeñas partículas definidas como signos, en resumidas cuentas, el ldeosema.

Cuando propuse la noción de ldeosema, trataba de entender el tipo de mediación que interviniera entre las estructuras de sociedad y las estructuras textuales al pasar del nivel de lo no-discursivo al nivel discursivo y textual. Dicho planteamiento implicaba el impacto de la ideología materializada. Por lo mismo, se tenía que hacer un análisis semiótico de estas prácticas y reorganizar las conclusiones según un esquema estructural; proceso imprescindible para que se pudiera al final articular juntos dos elementos originariamente tan heterogéneos. Los congresistas que me hayan leído se acordarán de que llamo ideosema a la estructura transferida directamente de la práctica social al proceso de la escritura. (Cros, 2010)

Los ideosemas deben entenderse como una estructura; redes de trazos discursivos de diferente naturaleza que constituyen la legibilidad y la forma de develar el aspecto social en el texto de ficción. En este orden de ideas, desde la teoría crosiana, se acepta entonces que la literatura está construida por un complejo juego de representaciones que actúan unos sobre los otros, cuyo origen está fuera del texto y se manifiestan en prácticas sociales, ideológicas y discursivas diversas y particulares. Así pues, el ideosema determina la presencia de lo no-discursivo (prácticas sociales) y su relación con los discursos establecidos, reproducidos y transcritos en lo discursivo (el texto de ficción). Al respecto, vale la pena aclarar que:

Estos fenómenos de estructuración reciben el nombre de articuladores semióticos cuando se trata de prácticas sociales o discursivas fuera del texto, y articuladores discursivos cuando se trata del texto, constituyendo el ideosema la relación entre el articulador semiótico y discursivo, ideosema que pasa a designar a la vez el punto de origen de la estructuración y los elementos que, en el texto, reproducen ese origen. (Chicharro, 2009)

Para sustentar esto, Cros pone como ejemplo la manera en que las prácticas sociales, discursivas y no discursivas, interfieren en la producción formal de la literatura española e hispanoamericana. Así pues, el hispanista francés demuestra sus planteamientos al analizar ciertas prácticas inquisitoriales en El Buscón; religiosas de la cárcel y ejecuciones de la justicia en El Guzmán de Alfarache y la relación entre el "yo" y el "él" en la confesión como práctica social de la inquisición en El lazarillo de Tormes. Con esto, Cros nos advierte que el sujeto además de que habla, es hablado en su discurso sin que él lo sepa. En este sentido, la cuestión que se plantea es saber quién habla en el sujeto hablante y cómo esas diferentes palabras se dan a oír en él. Lo anterior permite introducir una cuestión que es relevante: la importancia del texto de ficción a nivel formal. Esto en la medida en que su configuración estructural, sirve como mecanismo para dilucidar un sistema plurisistémico, ideológico y semiótico-discursivo en donde se aloja un sujeto cultural particular.

\section{II \\ A propósito de la novela-testimonio y la novela intrahistórica}

La inclusión de formas testimoniales en las obras de ficción aquí señaladas, resulta ser de relevancia para este ejercicio reflexivo. De manera general, pero sin ser reduccionista, a este tipo de narrativa se le ha catalogado como un género literario particular: "literatura testimonial". La novela de Miguel Barnet, Biografía de un cimarrón, ha sido señalada 
como una de las pioneras en el nacimiento de este tipo de novelística. Si bien, mi interés no es extenderme en exponer toda la teoría que existe al respecto, sí quiero señalar algunas características que permiten enfocar mi interés investigativo.

En este sentido, quiero traer a colación algunos de los postulados elaborados por Begoña Huertas Uhagón ${ }^{5}$ en su ensayo intitulado: El postboom y el género testimonio. Miguel Barnet. Esto en la medida en que se refiere al papel que desempeña el protagonista de la narración al contar su propia historia. ${ }^{6}$ La finalidad consiste en advertir el cambio en la elección del narrador. Uno interno, que permite dar una mayor relevancia a la focalización interna al dar "voz a los sin voz, a los silenciado" y así amplificar el "discurso de los excluidos", por un lado; uno omnisciente, y que había sido muy utilizado por los escritores del Boom Latinoamericano, por otro. Al respecto, la autora nos dice lo siguiente:

El testimonio centra su razón de ser, precisamente, en la conexión directa con la realidad extratextual, los elementos del relato tienen su correspondencia inmediata en el mundo exterior al texto. Por otra parte, el enlace de estas obras testimoniales con un referente histórico concreto se realiza a través de un plano individual. Es la mirada centrada en lo particular, en lo cotidiano, la que revelará un panorama más amplio, abarcador de una época. En este sentido, la mirada narrativa del testimonio, al concretar no sólo la realidad del relato sino su punto de enunciación, se diferencia una vez más del tratamiento globalizador propiciado por la mirada omnisciente del narrador del "boom'. (Huertas Uhagón, 1994, p. 167)

De igual manera, parafraseando a José Ismael Gutiérrez en su texto Miguel Barnet y su

5 Nacida en Gijón en 1965 es una escritora española, novelista y filóloga. Es doctora en Filología Hispánica por la Universidad Autónoma de Barcelona de Madrid. En 1993 ganó el Premio Casa de las Américas por su obra: Ensayo de un cambio: la narrativa cubana de la década de los 80 . Además, ha publicado las novelas: Déjame morir en paz (1998); Por eso envejecemos tan deprisa (2001); En el fondo. Pide una copa paga Proust (2009); Una noche en Amalfi (2012); El desconcierto (2017)

6 La narración en primera persona que caracteriza el testimonio cumple con la función de acercarnos, como lectores, al discurso del personaje participativo. (Ortiz, 1996, pág. 372) concepción de la "Novela-testimonio"7 podemos anotar las siguientes características:

1. La novela-testimonio se propone el desenmascaramiento de la realidad. Toma los hechos principales que han marcado la sensibilidad de una sociedad y los pone en boca de uno de sus protagonistas.

2. Respecto a la técnica narrativa hay una suspensión del "yo" en el uso del narrador. No hay juicios de este, sino que el autor deja que los protagonistas adquieran una voz propia.

3. El sentido histórico en la narración adquiere gran importancia.

4. La labor investigativa del escritor es muy importante. Este tiene que desvelar "la otra cara de la realidad".

5. Su punto más delicado lo encarna el uso del lenguaje: palabras, tono, inflexiones, sintaxis, etc.

De lo anterior resulta notable resaltar dos aspectos. El primero, la importancia del testimonio como una forma narrativa en la ficcionalización de la realidad y que responde a la pregunta del cómo se está contando. En ese sentido, corresponde al plano estructural del texto. El segundo, hace referencia a la relación existente entre lo testimonial y las múltiples maneras de reevaluar la Historia, de ficcionalizarla. De la misma manera, unida a estos dos aspectos, es importante resaltar la importancia que posee la idea de dotar de una voz a aquellos que han sido silenciados por discursos oficiales y así "develar la otra cara de la realidad". Esto en la medida en que la narrativa testimonial sirve para "dar voz a los que no la tienen para que así expresen directamente, y, como dice María Teresa Uribe, de una manera simple y franca, la otra historia de Colombia (en el caso de esta reflexión). ${ }^{8}$ (Ortiz, 1996, p. 372)

La historiografía como una forma discursiva ofi$\mathrm{cial}^{9}$ es una manera de acercarse a ese tiempo

\footnotetext{
$7 \quad$ Al respecto ver: Gutiérrez, J. I. (1993). Miguel Barnet y su concepción de la "Novela-Testimonio". Revista de Filología Universidad de Laguna, pp. 105-103.

8 Paréntesis mío.

9 Obviamente la historia oficial legitima, pero tiene un carácter mutable que también deslegitima lo antes legitimado [...] El Estado impone la historia oficial en los textos oficiales de historia para la educación escolar y en los monumentos en las plazas. Lo hace también al poner los nombres de las calles, al
} 
ya vivido, pero no es la única, ni tampoco la más legítima. Literaturizar la Historia es otra manera de aproximarse a los acontecimientos del pasado para reinventarlos. Así pues, la literatura al igual que el discurso historiográfico tienen algo en común: la narratividad. En este sentido, se podría decir que tanto la narratividad de lo histórico como la narratividad de lo literario tienen en común la imaginación, y, es esto, para los fines pertinentes de esta reflexión un aspecto relevante. Asimismo, nos recuerda Santiago Colás, citado por Lucía Ortiz que:

[...] el testimonio, como práctica y representación, es el resultado de un deseo, deseo de dignidad o de una consciencia de los límites artificiales y materiales impuestos por un Estado opresivo y oligárquico que se ha encargado de reprimir ese deseo [...] Los testimonios estudiados aquí son una forma alternativa de reescribir la historia desde la perspectiva de sus protagonistas más afectados. (Ortiz, 1996, p. 374)

Ahora bien, ¿cómo articular esta forma narrativa testimonial con la preocupación por ficcionalizar la historia, a partir del punto de vista de los excluidos por la Historia oficial? Considero que una posible respuesta es la revisión de los planteamientos elaborados por la profesora Luz Marina Rivas al respecto y que denomina: novela intrahistórica. Debo aclarar que mi interés no radica en ubicar las novelas de Miguel Torres y Pablo Montoya en un género o subgénero literario particular, sino que, mi propósito está en hacer notar como el texto de ficción transcribe ciertas prácticas sociales y discursivas en estructuras formales particulares en la narración.

Entonces, ¿Por qué hablar de narrativa-testimonial y novela intrahistórica? Primero, para contextualizar al lector con categorías que serán luego una base para mi propia reflexión. Y segundo, para plantear la idea de que el testimonio, como práctica y representación, es un ideosema estructurante que permite observar el develamiento de un sujeto cultural intrahistórico en las novelas de Miguel Torres y Pablo Montoya Campuzano: El incendio de abril y La sombra de Orión.

¿Qué sería entonces la novela intrahistórica? Esta denominación, como enuncié párrafos atrás, es una propuesta teórica realizada por la profesora Luz Marina Rivas y hace referencia a un subgénero que se desprende de la llamada novela histórica. De esta manera, aparece "como una vía para narrar el pasado desde las perspectivas de los marginados del poder, del pueblo según Unamuno, de los vencidos, los que no han participado en el hacer de la gran Historia, con mayúscula, entendida como la historia política, escrita desde el punto de vista del príncipe, como diría Michel de Certeau (1985)." (Rivas, 2004, p. 63)

Entonces, es posible afirmar que la novela intrahistórica centra su interés en darle voz a los personajes que han sido subordinados en las narraciones históricas de carácter heroico. Una obra de este tipo se preocupa por ficcionalizar la experiencia de las minorías, en la medida en que también son actores que escriben una historia posible. Ahora bien, este tipo de novela no es, evidentemente, un discurso de tipo historiográfico. De manera paralela, como obra de ficción que es, tiene su propia poética, caracterizada por la profesora Rivas (2004) de la siguiente manera:

a. Se caracteriza por la creación de personajes ficcionales subalternos.

b. Se narra de manera frecuente en primera persona.

c. Se ficcionaliza la historia de lo cotidiano.

d. Existe una apropiación de ciertos géneros literarios y discursivos de la intimidad y de los márgenes (contraliteraturas) por ejemplo: diarios, testimonios, relatos autobiográficos, cartas, etc.

e. Hay una apropiación de lenguajes y formas de la cultura popular: oralidad, mito y distintas formas de la cultura de masas.

oficializar el uso de un nombre en una moneda; lo hace en los rituales protocolares de los representantes de la autoridad, como las ofrendas florales a los héroes, la institución de fechas patrias, la decisión de hacer determinados homenajes. (Rivas, 2004, p.74) 
III

\section{El testimonio como ideosema estruc- turante en El incendio de abril, de Miguel Torres y La sombra de Orión, de Pablo Montoya Campuzano}

A partir de lo explicado en los dos apartados anteriores, sugiero que en las novelas El incendio de abril y La sombra de Orión, la inclusión de formas testimoniales en la estructura narrativa sirven como ideosemas estructurantes que permiten develar un sujeto cultural intrahistórico. Así pues, esta lectura sociocrítica responde a la idea de que una práctica social como lo es la conciencia histórica se transcribe en una práctica textual particular: el testimonio.

Esta clave de lectura permite observar algunas resonancias en las dos novelas. El primer aspecto, hace referencia a la ficcionalización de hechos históricos particulares que han marcado el transcurso social de Colombia: El Bogotazo, en la novela de Miguel Torres; la Operación Orión, en la obra de Pablo Montoya. Como segunda característica, la inclusión de múltiples voces subalternas que narran, de manera paralela, dichos acontecimientos históricos. Finalmente, en correlación a la pregunta sobre el qué se narra, encontramos el cómo de lo narrado, lo que nos remite a la problemática del aspecto formal en la estructuración del texto de ficción.

La novela de Miguel Torres, El incendio de abril (2012), narra desde una multiplicidad de voces, la confluencia de las experiencias de los personajes que vivieron de primera mano las consecuencias del asesinato del líder político Jorge Eliecer Gaitán, el 9 de abril de 1948. Acontecimiento que fue el ápice de la violencia política que se venía gestando en Colombia, gracias a las diferencias irreconciliables de los dos partidos políticos tradicionales colombianos: Liberales y Conservadores. A nivel estructural, la novela se compone de tres apartados titulados: El día y la noche; La noche y La noche y el día. El primero de ellos está configurado a partir de 67 relatos que recrean la voz de muchos personajes que vivieron y padecieron El Bogotazo. Esta polifonía permite acercarse a un panorama diverso frente a lo que fue el magnicidio del líder político liberal. Así pues, un taxista, una empleada doméstica, un obrero, un estudiante, un profesor, un linotipista, un electricista y muchos protagonistas más, hacen parte de ese cúmulo de murmullos que cuentan de "primera mano" lo sucedido ese 9 de abril de 1948 en el centro de la capital colombiana.

Por su parte, el segundo apartado se centra en narrar la búsqueda que hace Ana Barbusse de su esposo Francisco, una de esas múltiples voces que experimentaron la violencia de El Bogotazo. Un pintor que ese día salió de su casa con la finalidad de entregar un cuadro que le había sido encargado de la figura de Gaitán y, de manera casual, en su camino fue sorprendido por la violencia desatada por el asesinato del líder político. De esta manera, la narración se centra en novelizar el recorrido que hace la protagonista en la búsqueda de su pareja sentimental por aquel averno en el que había sido convertido el centro de Bogotá.

El capítulo final, La noche y el día, muestra cómo algunas de las familias adineradas de la época vivieron, en medio del caos, el miedo a una posible revuelta popular y con ello el saqueo de sus propiedades. En la novela, dichas estirpes son representadas por ciertos apellidos distintivos de la época como lo eran: Santamaría, Urrutia, Umaña, Pombo, Quijano, entre otros. De esta manera, deciden refugiarse en una mansión deshabitada, propiedad de la familia Campuzano, y así evitar el peligro que representaba el odio de la "chusma energúmena" que deambulaba por las calles de los barrios opulentos de Bogotá.

La sombra de Orión (2021), escrita por Pablo Montoya Campuzano, es una novela que ficcionaliza la Operación Orión, un operativo militar ejecutado el 16 y 17 de octubre de 2002 en la comuna 13 (San Javier) en Medellín por el Ejército y la Policía Nacional de Colombia, en compañía de grupos paramilitares como el Cacique Nutibara, y cuya finalidad consistió en acabar la presencia de grupos guerrilleros urbanos de las Fuerzas Armadas Revolucionarias de Colombia (FARC), el Ejército de Liberación Nacional (ELN) y los Comandos Armados del Pueblo (CAP). Asimismo, la novela se estructura en nueve capítulos que dan un panorama muy completo de dicha intervención estatal. 
Al igual que la novela de Torres, el interés de Pablo Montoya es ficcionalizar un hecho histórico a partir de la recreación de las voces que fueron participes del mismo y que, de cierta manera, han sido olvidadas por el discurso historiográfico. Así pues, no se trata de incluir bajo parámetros estadísticos el número aproximado de las personas que fueron asesinadas, desaparecidas y torturadas en medio de la violencia producida como consecuencia de El Bogotazo y la Operación Orión. De manera paralela, lo que hacen estos dos escritores desde la ficción literaria, es dar cuerpo y voz a esos seres humanos que han sido silenciados, a esos subalternos que la Historia deja a un lado y no aparecen en los monumentos en las plazas públicas. Por consiguiente, dichos subalternos se asocian:

[...] a los márgenes, a las periferias o lugares distanciados de los centros de poder. El subalterno es con frecuencia el Otro, aquel desde quien no se producen los discursos hegemónicos, el objeto del que habla y no el sujeto que habla con la autoridad legitimada por Occidente, por el varón blanco, adulto y con poder económico. Los subalternos son las razas no blancas, los países del Tercer Mundo y del Cuarto Mundo, Oriente, las mujeres, los homosexuales, las clases bajas, en fin, todos aquellos que se sitúan de una manera u otra en una periferia. (Rivas, 2004, p. 81)

Para los fines pertinentes de este texto, centraré mi reflexión en solo uno de los capítulos. La Escombrera. Esto en la medida en que es en este apartado en donde se puede percibir con mayor detalle esa preocupación por ficcionalizar las voces de esos personajes situados en las periferias, en los bordes de los centros de poder. Además, porque es en este capítulo en donde se pueden observar de manera explícita las formas testimoniales a las que me he referido con anterioridad y que cumplen la funcionalidad de develar un sujeto cultural de naturaleza intrahistórica. ${ }^{10}$

\footnotetext{
10 "Podemos entonces acercarnos a conceptualizar la novela intrahistórica como la narración ficcional de la historia desde la perspectiva de los subalternos sociales, que aunque víctimas de la misma, no son agentes pasivos; tienen un bagaje histórico por vía de la tradición entendida como vínculo entre el pasado y presente dado por la costumbre y los modos culturales trasmitidos generacionalmente[...] La intrahistoria es, por lo tanto, una visión de la historia desde los márgenes del poder y tiene como protagonista a personajes cuya tensión entre espacio de experiencia o habitus y horizonte de espera resulta
}

Entonces, desde esta perspectiva, las formas testimoniales que son incorporadas en las dos novelas colombianas funcionan como ideosemas estructurantes al transcribir una práctica social a una textual. Con esto me refiero a que en las obras estos recursos narrativos permiten ficcionalizar acontecimientos históricos desde la perspectiva de los sin-nombre, de esos otros, los subalternos que mencionaba la profesora Rivas en párrafos atrás. Esto, en definitiva, permite reescribir la historia de personajes anónimos, de sus vidas privadas y de sus experiencias. Se podría afirmar que son relatos que se focalizan desde abajo, desde los márgenes, justo en las orillas.

En este orden de ideas es posible observar que, en El incendio de abril, en la primera parte, El día y la noche, existe una clara ejemplificación de lo que se acaba de señalar, puesto que este apartado se compone de sesenta y siete relatos narrados en clave testimonial, en los cuales emerge esa multiplicidad de voces, señalada párrafos atrás, y en donde se cuenta las maneras de sentir El Bogotazo. En relación con esto vale la pena aclarar dos aspectos que resultan relevantes. Primero, el uso de un narrador protagonista que cuenta desde su propia voz lo acontecido ese 9 de abril de 1948. Segundo, la inclusión de un título, con su respectivo subtítulo, en cada uno de esos testimonios. Veamos un ejemplo:

\section{Asdrúbal Peñaranda}

Desempleado. Una calle del barrio Las Ferias.

Cuando iba llegando a la casa, mi mujer me salió al encuentro con el hijo en brazos y me fue diciendo: Mijo, mataron a Gaitán. ¿Quién le dijo semejante bestialidad?, le pregunté. Lo acabo de oír por la radio, dijo ella sin parar de llorar. Yo sentí que se me encanijaban las manos, los pies, todo el cuerpo. No fue que se me salieran las lágrimas, es que cuando caí de rodillas en el andén y me tapé la cara ya estaba llorando. (Torres, 2012, p. 42)

Aquí, como en la totalidad de los más de sesenta relatos testimoniales, emerge un "Yo" que está sintiendo lo que está narrando, hay un desgarramiento al pronunciar las palabras, se siente con el cuerpo la experiencia del Bogotazo. Asimismo, la elección de nombrar esas voces es otorgarles un

en una conciencia del subalterno de un pasado y de un futuro muy distantes a los de la historia oficial." (Rivas, 2004, p. 88) 
posible rostro a aquellas personas que padecieron la violencia descarnada aquella fatídica tarde. No contento con ello, Miguel Torres ubica el lugar en donde se da el testimonio: "Una calle del barrio Las Ferias" y, de la misma manera, la ocupación que en ese momento desempeñaba el personaje. Al respecto, y volviendo a los planteamientos de Rivas, estos recursos narrativos permiten entonces hablar de intrahistorias en la medida en que en las narraciones:

[...] la perspectiva particular de los personajes desde su cotidianidad y subjetividad permite visualizar el componente emotivo, la manera afectiva como ellos se vinculan con los acontecimientos históricos, con las premisas morales de sus sociedades, con los rituales, con las creencias y las prohibiciones. Todo ello puede visualizarse en las formas mismas que adoptan las novelas para contar ese pasado, formas que permiten acceder a los relatos de la cultura que estructuran el sentir. (Rivas, 2004, p. 94)

Cualquier lector que se acerque a la primera parte de esta novela encontrará en cada uno de los testimonios lo siguiente: "Julio Romero. Preso. Cárcel de Correccionales". (Torres, 2012, p. 98). "Aurora Paz. Aseadora. Pieza de inquilinato. Loma de la Mosca". (p. 100). "Rubén Parra. Boticario. Droguería Alcalá. Belén". (p. 103). "Abel Pantano. Sargento del Ejército. Plaza Grande de Bogotá". (p. 118). "Cipriano Tibocha. Zapatero. Plaza de Nariño". (p. 157). Al respecto, es evidente la preocupación del autor por distinguir e individualizar cada una de las voces que se dan a oír en los testimonios. De igual manera, la elección de un narrador protagonista permite dar una visualización de cada una de las subjetividades de los personajes, de sus modos de pensar, sentir y existir.

De la misma manera, en el segundo apartado de la novela, La noche, aparece Ana Barbusse, otro personaje protagonista que cuenta su propia historia. Ella es una escritora que abandona su casa ubicada en La Candelaria para ir en la búsqueda de su marido, Francisco, quien justo esa tarde fatídica del 9 de abril salió a entregar un retrato al óleo del líder político Jorge Eliecer Gaitán. El escenario que propone Torres es una verdadera vorágine de la violencia, un laberinto dantesco cargado de horror, miedo y desesperación. Ahora bien, retomando la idea del testimonio como ideosema estructurante en la composición de las novelas, aparece en esta segunda parte de la obra la inclusión de una forma testimonial particular: la carta. Y esta como una tipología narrativa en la construcción de ese "Yo" intrahistórico que siente, que vive, que padece. De esta manera, al inicio de esta segunda parte de la novela se lee lo siguiente:

Querido: voy a salir a buscarte. Son más de las cuatro de la tarde ya no soporto más este encierro en la casa sin tener noticias tuyas. Desde mediodía, cuando estallaron los disturbios por el asesinato de Gaitán, no he tenido un segundo de sosiego. Interrumpí mi trabajo. Con qué ánimo iba a seguir escribiendo... Lo que está ocurriendo es espantoso. Nunca llegué a imaginarme que iba a pasar por una situación como la que estoy viviendo en estos momentos. No quiero ni pensar que te haya pasado algo malo. Destierro esos pensamientos que me torturan el corazón y prefiero imaginar que te encuentras en algún lugar seguro, a la espera de que la situación se calme para venir corriendo a casa. Voy a salir. Iré al negocio del señor Porras. Dios quiera que este terrible suceso te haya sorprendido mientras entregabas el retrato de Gaitán. Precisamente ese retrato que terminaste de pintar ayer. Qué triste casualidad. Lo que más anhelo es encontrarte allá y regresar contigo. Contigo soy capaz de enfrentar todos los peligros. Te amo. Ana. (Torres, 2012, p. 199)

En este fragmento se puede observar cómo el uso de un narrador interno/protagonista configura un "Yo" femenino que cuenta su propia angustia a través del uso de la carta. Hacerlo desde esta forma de escritura permite suponer la idea de un acto de confidencia consigo mismo. Dicha tipología textual funciona como una "tecnología del yo"11 y, por ende, se puede aseverar que "El relato de sí es el relato de la relación consigo mismo", siguiendo a Foucault, ${ }^{12}$ y de esta manera termina siendo una práctica discursiva que devela el sentir de Ana Barbusse en El Bogotazo. De esta manera,

11 Estas, entendidas de manera general, como operaciones que se ejecutan sobre los cuerpos, las almas, los sentimientos, las conductas y las formas de ser en los sujetos para lograr una transformación de sí. Ver: Foucault, Michel (1990). Tecnologías del yo: y otros textos afines. Barcelona: Paidós. 12 "La carta que se envía actúa, mediante el gesto mismo de la escritura, sobre quien la remite, así como también, mediante la lectura y la relectura, sobre aquél que la recibe. En esta doble función, la correspondencia se halla totalmente próxima a los hypomnémata, y con frecuencia es muy similar." Ver: «https://elcuadernocomodispositivohome.files.wordpress. com/2019/02/foucault-la-escritura-de-sc3ad.pdf ». 
es posible afirmar que: “Escribir es, por tanto, «mostrarse», hacerse ver, hacer aparecer el propio rostro ante el otro. Y por ello hay que entender que la carta es a la vez una mirada que se dirige al destinatario (por la misiva que recibe, se siente mirado) y una manera de entregarse a su mirada por lo que se le dice de uno mismo. La carta habilita, en cierto modo, un cara a cara". (Foucault, 1999) De la cita anterior, resulta importante resaltar el papel que juega la "escritura de sí" como una práctica íntima en la construcción de la subjetividad y que, para el caso particular de la novela de Torres, refuerza el postulado de la importancia en la inclusión de este recurso a nivel formal en El incendio de abril, ya que permite privilegiar la mirada de lo histórico desde las experiencias personales de aquellos personajes que vivieron de primera mano las consecuencias del asesinato de Jorge Eliecer Gaitán.

Así pues, el uso de la carta por parte de Ana Barbusse, refuerza la idea de que el testimonio, como una práctica social y discursiva, se transcribe en una textual: la creación ficcional (ideosema). En este orden de ideas, la elección de una focalización interna por medio de un personaje protagonista y el uso de esa "escritura de sí", que permite realizar el discurso epistolar, sugieren la preocupación del autor por develar las voces de sujetos culturales intrahistóricos, si entendemos por esta última noción que:

[...]narra la historia colectiva desde lo anónimo y lo privado, desde los márgenes del poder; es una vía para la búsqueda de la identidad individual y colectiva a través de la revisión de la historia desde una perspectiva cargada de componentes afectivos. Lo histórico es concebido dentro de la novela intrahistórica como un todo, en el cual lo cotidiano, lo ritual, lo doméstico, la vida interior, la cultura, son tan historizables como la política, la economía o las guerras, en el sentido de que ese todo que se alimenta de la tradición y de la vida cotidiana, define la identidad dentro de cada período histórico. (Rivas, 2004, p. 101)

De igual manera, la novela de Pablo Montoya Campuzano es muy propositiva al respecto. En ella se ficcionaliza la ofensiva militar que se ejecutó en Medellín, los días 16 y 17 de octubre de 2002, en la comuna 13, San Javier. Operativo, dicho sea de paso, en donde la Fuerza Pública (Ejército y Policía Nacional de Colombia) en colaboración con grupos paramilitares de extrema derecha quisieron "erradicar" la presencia de grupos de Milicias Urbanas (FARC, ELN y CAP). ${ }^{13}$ Operación Orión fue el nombre que se le otorgó a este suceso histórico en donde al menos hubo más de ochenta civiles heridos, diecisiete homicidios ejecutados por parte de las fuerzas de la "Seguridad Democrática"14, más de setenta personas asesinadas por las Autodefensas Unidas de Colombia (AUC), decenas de personas torturadas, y se podría hablar de casi una centena de desapariciones forzadas. ${ }^{15}$

En relación con la novela La sombra de Orión me referiré, como lo enuncié en párrafos anteriores, al capítulo VIII titulado La Escombrera. Esto teniendo en cuenta el punto central de este artículo. Entonces, lo que quiero subrayar del texto es que, al igual que la primera parte de El incendio de abril de Miguel Torres, Pablo Montoya opta por el uso del testimonio como un recurso estilístico válido para ficcionalizar las voces de los desaparecidos en el ya mencionado operativo militar. Los límites entre el lenguaje literario y el habla cotidiana se difuminan en el uso de ese recurso formal. Aparecen, al igual que en la novela sobre El Bogotazo, narradores protagonistas que usan la diégesis en primera persona para otorgarle mayor verosimilitud a lo narrado. Son un total de veintiséis testimonios que desde el sentir ${ }^{16}$ cuentan la experiencia vivida en la Operación Orión. De esta manera, emerge una conciencia histórica que

\footnotetext{
13 Fuerzas Armadas Revolucionaras de Colombia, Ejército de Liberación Nacional y Comando Armados del Pueblo; en su respectivo orden.

14 Política de Estado ejecutada bajo el mandato del expresidente Álvaro Uribe Vélez (2002-2010).

15 Al respecto ver: «https://verdadabierta.com/ operacion-orion-la-verdad-diez-anos-despues/».

16 "La interacción entre las distintas formas sociales no se establece como intercambios sistemáticos entre unidades fijas, sino más bien tiene que ver con lo que verdaderamente se está viviendo, no sólo lo que se piensa que se está viviendo. Esa interacción va más allá de la ideología o de la visión de mundo. Involucra unas estructuras del sentir o estructuras de la experiencia. Estas estructuras se componen de elementos que conforman un grupo de relaciones internas que se interconectan y pueden estar en tensión, elementos específicamente afectivos de la conciencia y las relaciones, y no sentimiento contra pensamiento, sino pensamiento tal como es sentido y sentimiento tal como es pensado; una conciencia práctica de tipo presente, dentro de una continuidad viviente e interconectada." (Rivas, 2004, p. 90)
} 
reescribe la vida de personajes anónimos desde sus propias voces. Este es, sin lugar a duda, un gran logro en las dos novelas.

En el apartado señalado son los muertos los que hablan. Pablo Montoya toma el caso particular de La Escombrera ${ }^{17}$ para desenterrar los miles de desaparecidos que yacen bajo el polvo, el ladrillo y la tierra, y les permite contar su historia. Con esto se le da una voz a los olvidados por la gran Historia. Estamos, de nuevo, frente a un recurso formal que permite observar ese sujeto cultural intrahistórico que he enunciado a lo largo de este documento. Existe una preocupación en los dos autores por literaturizar acontecimientos históricos ${ }^{18}$ con una toma de posición marcada: situarse al lado de los marginados. Así pues: "se propone un nuevo modo de narrar comprometido. De todas maneras [...] Los personajes de este texto (el testimonio) ${ }^{19}$ se convierten en voces colectivas que desde diferentes perspectivas nos van sumergiendo en una época de crisis, permeada por el terror y la muerte. (Ortiz, 1996, p. 351)

Al inicio del capítulo mencionado es posible leer lo siguiente:

Vengo del fuego y voy hacia él. Soy tierra calcinada. En mi sangre, brasas sin tregua. Resuenan las reyertas en mí

17 Es una montaña de residuos, que comprende dos escombreras (San Javier y Bioparques) y una arenera (EI Cóndor), y se sitúa en el límite de la Comuna 13. Es probablemente la fosa común más grande de América Latina. Allí fueron a parar cientos de civiles desaparecidos en la Operación Orión. Además, terminó siendo un lugar en el cual sepultaban los cadáveres de miles de personas asesinadas por parte del conflicto armado interno entre los grupos guerrilleros de extrema izquierda, los grupos paramilitares de extrema derecha y el Ejército Nacional de Colombia.

18 Al respecto, es interesante observar cómo en algunas novelas publicadas desde el inicio del siglo XXI existe una preocupación por ficcionalizar la historia. Asimismo, este es un tema en el cual estoy adelantando una investigación y desde donde se desprende este artículo. Satanás de Mario Mendoza (2002); El eskimal y la mariposa de Nahum Montt (2004); El crimen del siglo de Miguel Torres (2006); Los ejércitos de Evelio Rosero (2007); Desaparición de Gustavo Forero Quintero (2012); El incendio de abril de Miguel Torres (2012); La invención del pasado de Miguel Torres (2016) y La sombra de Orión de Pablo Montoya Campuzano (2021) ejemplifican lo que acabo de enunciar.

19 Paréntesis mío. como si yo fuera la extensión de un desagravio jamás consumado. Me llamo Ofelia María Cifuentes y estoy en La Escombrera. Aquí solo hay una oscuridad compacta. Polvo, piedras, basura. Yo misma mezclada con todo ello. Y eso que soy ahora, arde sin cesar. Pero deseo apagarme. Que no haya más fragor. Ni en mí. Ni en nadie. Ni en nada. Recuerdo apenas el afuera. ¿Cómo es el viento? ¿Cómo el agua? ¿Cómo la luz? Todo lo he olvidado y cuando los evoco, el fuego me invade. También me olvidé del tiempo. O quizás sea él este silencio y esta parálisis. Y olvidé el rostro de los míos. Hasta el de los que me arrojaron aquí. ¿Sabes por qué lo hicieron, Pedro? Porque les daba tinto a los milicianos. Porque coqueteé con uno de ellos, al que le decía Aníbal. Porque me enamoré de él y nos besamos e hicimos el amor en el baño de mi casa. (Montoya Campuzano, 2021, p. 299)

El relato de Ofelia María Cifuentes se hace desde los rincones de la muerte. Es su sentir el que de golpe se nos narra. El sentimiento de abandono es innegable. Remece al lector. Es un personaje que ha sido asesinado, a lo mejor torturado, para luego ser sepultado en La Escombrera. Su culpa fue haber tenido un romance con un miliciano. Amar fue la causa de su muerte. Al respecto, resulta interesante ver cómo el autor elige que sea su propia voz la que se haga presente desde el fondo vacío en donde se encuentra esta mujer. Aquí emerge como una reacción contra el olvido, de nuevo, y al igual que en la novela de Miguel Torres, la intrahistoria. Y es que para el gobierno de turno lo importante fue el hecho histórico de haber "limpiado" la comuna San Javier de las guerrillas, sin importar el precio que se debía pagar, que en este caso fueron los muertos. ¿Cuántas fueron las víctimas de desaparición forzada? ¿Cuántos los torturados? ¿Cuánta la sangre derramada? Los logros fueron los números, las cifras, los resultados. El poder de la literatura radica en la posibilidad de darle un rostro a esos seres humanos que perecieron ese fatídico 16 y 17 de octubre de 2002. Más adelante, otro de los testimonios nos deja las siguientes palabras:

No es fácil hablar desde mi condición. Decir quién soy sin saber en dónde estoy. Pero sé que me llamo Tulio Andrés Acevedo. Podría describir qué hacía cuando deambulaba por los barrios. Quiénes eran mis padres, mis hermanos, mis amigos. Esas cosas no son difíciles de contar y creo que al hacerlo me sentiría vivo. Aunque la vida para mí ya no es posible. Pero lo que no sabría explicar es qué ha pasado con mis huesos. En qué lugar exacto están ahora. Sé que 


\section{PABLO MONTOYA}
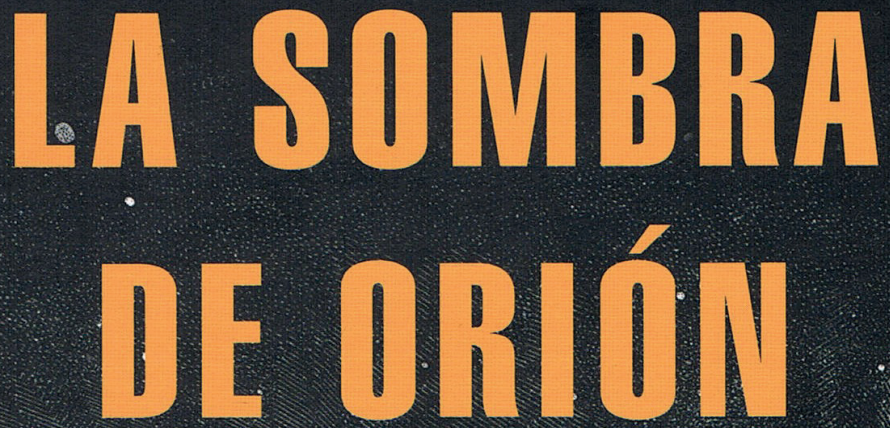

o.
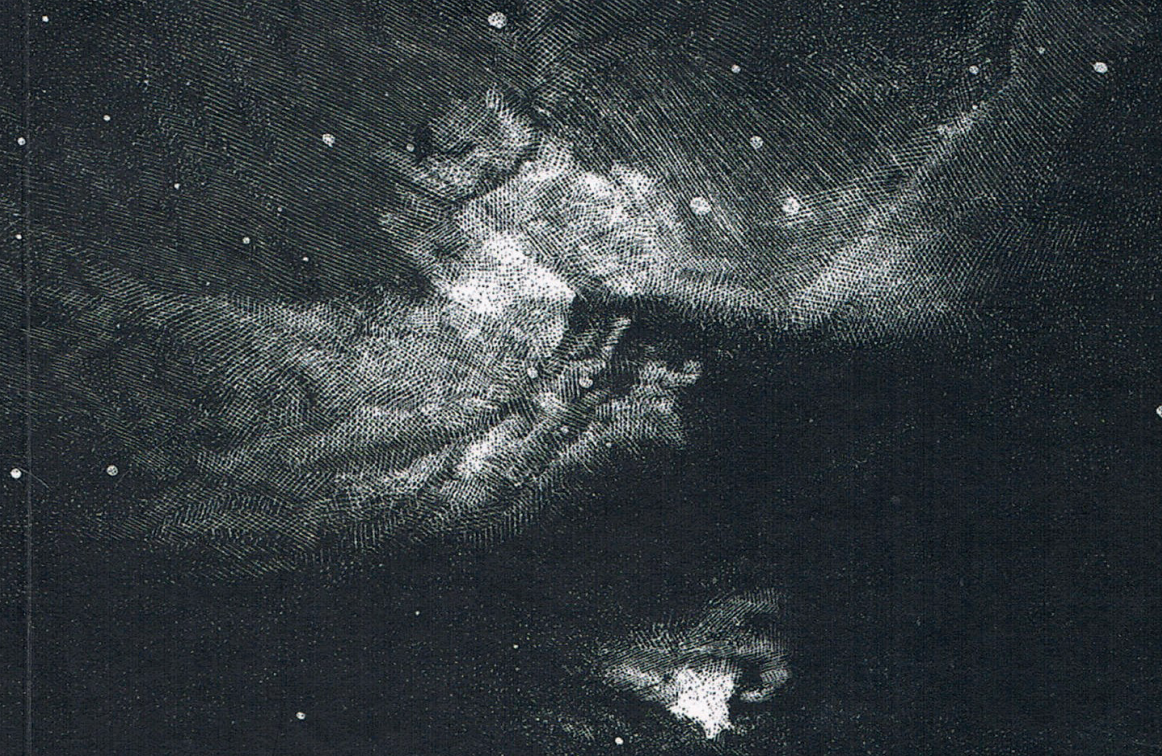

6

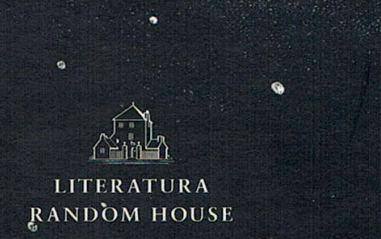

Imagen 1. Portada del libro La sombra de Orión, de Pablo Montoya. 
tengo algo de memoria como para referir qué ocurrió.

Son recuerdos que sirven para entender que mi tiempo pasó en La Comuna. En esos días me bandeaba vendiendo cuadernos y lápices y otros artículos de papelería. Una vez, al regresar a mi casa en Belencito, me pegaron el tiro en la cabeza. Varios brazos levantaron mi cuerpo y lo introdujeron en el maletero de un carro. Luego lo sacaron y lo lanzaron a La Escombrera. (Montoya Campuzano, 2021, p. 319)

En La sombra de Orión quienes hablan son los muertos y los desaparecidos, como el caso de Tulio Andrés Acevedo, a quién lo mataron de un tiro en la cabeza cuando llegaba a su casa, luego de su jornada laboral. De esta manera, es la voz de la muerte la protagonista. Además, es una espiral que afecta también a los familiares y amigos de las víctimas de esa violencia descarnada producto de los conflictos internos que han afectado, y aún afectan, la historia de Colombia. Por consiguiente, en esos testimonios que componen el apartado VIII se escuchan una multiplicidad de voces que, como murmullos, piden ser escuchados. Emerger del polvo y del olvido para hacer presencia desde la ausencia. En este orden de ideas, la literatura está en la posibilidad de contar otra historia posible, es otra opción para interpretar el pasado y así resignificarlo. El texto de ficción, de esta manera, permite narrar desde otras perspectivas acontecimientos históricos que aún retumban en el imaginario social de los colombianos. Finalmente, frente a la impunidad, aparece la memoria. Esto en la medida en que las prácticas testimoniales que se transcriben en la novela de Miguel Torres y Pablo Montoya Campuzano funcionan como ideosemas estructurantes, al permitir el descubrimiento de la toma de posición de los autores al develar un sujeto cultural intrahistórico, que permite reevaluar la materia histórica y, siguiendo a Bertolt Brecht en su poema Preguntas de un obrero que lee, dejar al descubierto tantas historias y tantas preguntas...

\section{Referencias}

Abierta, V. (16 de octubre de 2012). Verdad Abierta.com. Obtenido de Verdad Abierta.com «https://verdadabierta. com/operacion-orion-la-verdad-diez-anos-despues/»

Brecht, B. (03 de 21 de 2021). La caja de herramientas: biblioteca virtual de la Unión de Juventudes Comunistas de España. Obtenido de La caja de herramientas: biblioteca virtual de la Unión de Juventudes Comunistas de España: «http://archivo.juventudes.org/bertolt-brecht/ preguntas-de-un-obrero-que-lee»

Carpentier, A. (1984). Presentación. En R. González Echevarría, Historia y ficción en la narrativa hispanomanericana (pp. 15-48). Venezuela: Monte Avila Editores.

Chicharro, A. (2012). Entre lo dado y lo creado: una aproximación a los estudios sociocríticos. Varsovia: Instituto de Estudios Ibéricos e Iberoamericanos de la Universidad de Varsovia.

Chicharro, A. (2009). Prólogo. En E. Cros, La sociocrítica (pp. 11-22). Madrid: Arco/Libros S.L.

Cros, E. (2003). El sujeto cultural. sociocrítica y psicoanálisis. Medellín: Fondo Editorial Universidad EAFIT.

Cros, E. (2 de abril de 2010). Sociocritique. Obtenido de sociocritique: «http://www.sociocritique.fr/»

Foucault, M. (1999). Obras esenciales. Barcelona: Paidós. Obtenido de «https://elcuadernocomodispositivohome.files.wordpress.com/2019/02/foucault-la-escritura-de-sc3ad.pdf»

Foucault, M. (2008). Tecnologías del yo y otros textos afines. Buenos Aires: Paidós.

García de la Sienra, R. (2002). Edmond Cros, el sujeto cultural. Sociocrítica y psicoánalisis. Iztapalapa, 444-446.

Huertas Uhagón, B. (1994). El Postbomm y el género testimonio. Miguel Barnet. CAUCE. Centro de filología, comunicación y sus didácticas, pp. 165-175.

Montoya Campuzano, P. (2021). La sombra de Orión. Bogotá: Penguin Random House Grupo Editorial. 
Ortiz, L. (1996). Narrativa testimonial en Colombia: Alfredo Molano, Alfonso Salazar, Sandra Afanador. En M. M.

Jaramillo, B. Osorio, \& Á. I. Robledo, Literatura y cultura:

narrativa colombiana del siglo XX. Volumen II. Diseminación,

cambios, desplazamientos (pp. 339-377). Bogotá: Ministerio de Cultura.

Pascal Kadio, K. (2017). La sociocrítica y la problemática del sujeto cultural. Sociocriticism, pp. 189-212.

Rivas, L. (2004). La novela intrahistórica. Mérida: El otro, el mismo.

Torres, M. (2012). El incendio de abril. Bogotá: Alfaguara. 